\title{
Osteopenia of prematurity
}

\author{
J R JAMES, P J CONGDON, J TRUSCOTT, A HORSMAN, AND R ARTHUR
}

Regional Neonatal Surgical and Intensive Care Unit and MRC Mineral Metabolism Unit, The General Infirmary, Leeds

SUMMARY Bone mineral content of the forearm was measured by photon absorptiometry in 17 preterm infants at a postconceptional age of 40 weeks. Radiographs of the forearm were assessed by Koo's method and plasma alkaline phosphatase activity was also measured at this time. Bone mineral content was significantly but weakly correlated with Koo score and was not significantly correlated with alkaline phosphatase activity. Neither of these two commonly used investigations accurately predicts the presence of underlying bone disease.

Compared with 15 full term infants the preterm infants had significantly lower values of bone mineral content, palpated ulnar length, and crown-heel length. After adjusting for weight and ulnar length the preterm group still had a significantly lower mean value of bone mineral content than the full term group. Accurate diagnosis of osteopenia of prematurity requires photon absorptiometry, with bone mineral content assessed relative to body weight or ulnar length.

Bone disease (rickets of prematurity or osteopenia) is now being increasingly recognised in surviving preterm infants. ${ }^{1}$ Diagnosis is usually based on either radiological abnormalities ${ }^{2}$ or rises in plasma alkaline phosphatase activity. ${ }^{3}$ Radiological diagnosis is likely to be imprecise because the assessment is subjective and a major loss of bone mineral might have to occur before characteristic changes are apparent. ${ }^{4}$ Although raised plasma alkaline phosphatase activity is observed in association with frank radiological rickets, ${ }^{3}$ activities change with postnatal age, and it is difficult to decide what activity represents underlying bone disease. ${ }^{56}$

Bone mineral content can be measured directly with photon absorptiometry, and we have previously shown that an absorptiometer specifically developed and calibrated for small infants is very precise and accurate. ${ }^{7}$ We have compared radiographic and biochemical evidence for bone disease with measurements of bone mineral content in a group of preterm infants on reaching the postconceptional age of 40 weeks, with the aim of assessing the diagnostic accuracy of these two commonly used investigations. We have also compared bone mineral content and other measurements related to body size of preterm infants at 40 weeks with similar measurements of full term infants near the time of birth to assess whether osteopenia of prematurity contains a component that is independent of reduced growth.

\section{Patients and methods}

Fourteen boys and three girls born at or before 32 weeks and eight boys and seven girls born at term were investigated after informed parental consent had been obtained. The excess of boys in the preterm group was not the result of selection but reflected the population in the neonatal unit when the study was undertaken. Sex, gestational age, and weight at birth are given in Tables 1 (preterm infants) and 2 (full term infants). Gestational age was assessed according to the mother's last menstrual period and clinical criteria at birth. Investigations were performed within five days of the postconceptional age of 40 weeks in the preterm infants and less than three days after birth in the full term infants. The investigations, which were carried out with the approval of the hospital ethics committee, comprised for the preterm group photon absorpiometry (involving measurement of ulnar length) and radiography of the forearm and measurement of crown-heel length and plasma alkaline phosphatase activity and for the full term group photon absorptiometry and measurement of crown-heel length; radiographs were not taken in the full term group for ethical reasons. All infants received supplemental vitamin D (400 IU daily) with oral feeds using a proprietary milk formula (Osterfeed).

The bone mineral content of the right forearm 
872 James, Congdon, Truscott, Horsman, and Arthur

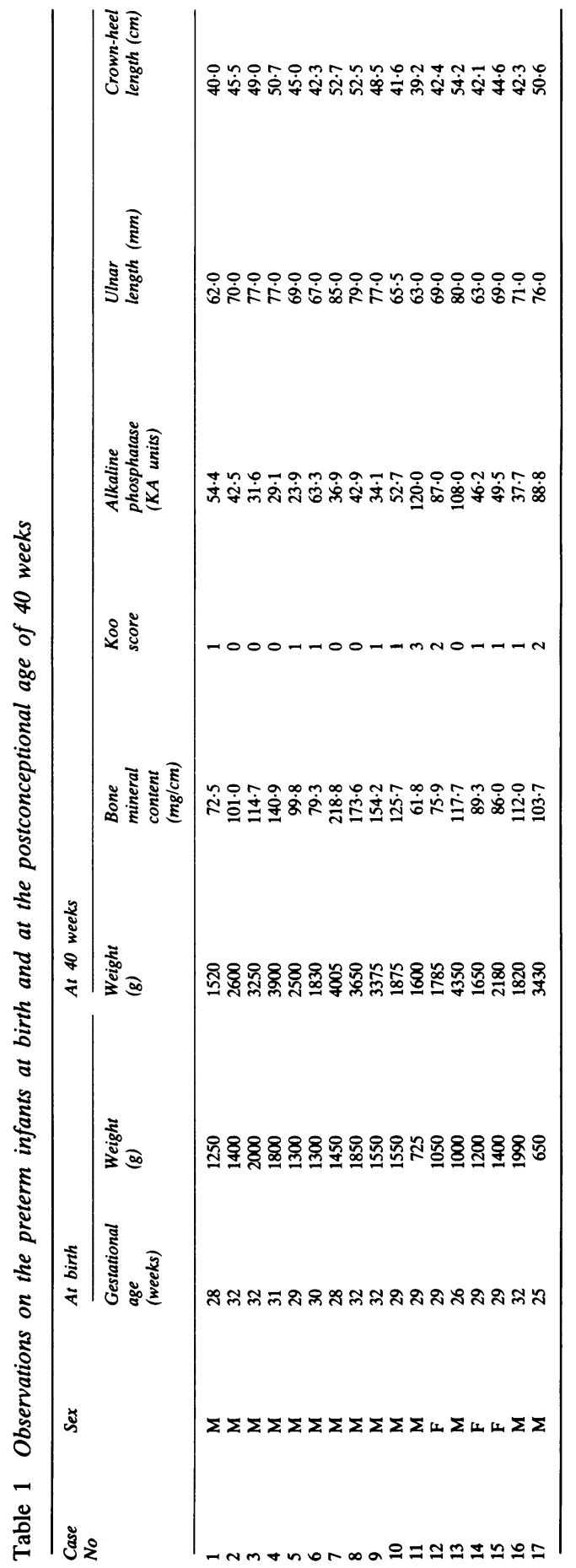


Table 2 Observations on the full term infants at birth

\begin{tabular}{|c|c|c|c|c|c|c|}
\hline $\begin{array}{l}\text { Case } \\
\text { No }\end{array}$ & Sex & $\begin{array}{l}\text { Gestational } \\
\text { age (weeks) }\end{array}$ & $\begin{array}{l}\text { Weight } \\
\text { (g) }\end{array}$ & $\begin{array}{l}\text { Bone } \\
\text { mineral } \\
\text { content }(\mathrm{mg} / \mathrm{cm})\end{array}$ & $\begin{array}{l}\text { Ulnar } \\
\text { length ( } \mathrm{mm})\end{array}$ & $\begin{array}{l}\text { Crown-heel } \\
\text { length }(\mathrm{cm})\end{array}$ \\
\hline 1 & $\mathbf{M}$ & 39 & 3710 & 194.0 & $85 \cdot 0$ & 53.0 \\
\hline 2 & $\mathbf{F}$ & 40 & 3200 & $172 \cdot 2$ & $80 \cdot 0$ & $52 \cdot 5$ \\
\hline 3 & $\mathrm{~F}$ & 40 & 4440 & 205.4 & $86 \cdot 0$ & $60 \cdot 0$ \\
\hline 4 & $\mathbf{M}$ & 40 & 3430 & $201 \cdot 1$ & $85 \cdot 0$ & $53 \cdot 5$ \\
\hline 5 & $\mathbf{M}$ & 38 & 2980 & 188.4 & $77 \cdot 0$ & $51 \cdot 0$ \\
\hline 6 & $\mathrm{~F}$ & 40 & 3390 & 192.9 & $81 \cdot 5$ & $53 \cdot 0$ \\
\hline 7 & $\mathbf{M}$ & 40 & 4200 & $196 \cdot 5$ & $83 \cdot 5$ & 58.0 \\
\hline 8 & $\mathbf{M}$ & 41 & 3700 & $202 \cdot 3$ & $80 \cdot 0$ & $51 \cdot 0$ \\
\hline 9 & $F$ & 40 & 4600 & 222.4 & 90.0 & $60 \cdot 0$ \\
\hline 10 & $\mathbf{M}$ & 40 & 3030 & 214.0 & 78.0 & 49.0 \\
\hline 11 & $F$ & 40 & 2730 & $182 \cdot 2$ & $76 \cdot 0$ & $56 \cdot 0$ \\
\hline 12 & $F$ & 40 & 3000 & $176 \cdot 2$ & $78 \cdot 0$ & $51 \cdot 0$ \\
\hline 13 & $\mathbf{M}$ & 40 & 3550 & 182.6 & $81 \cdot 0$ & 53.0 \\
\hline 14 & $\mathbf{M}$ & 40 & 3680 & $202 \cdot 0$ & 84.0 & 51.0 \\
\hline 15 & $\mathrm{~F}$ & 40 & 3450 & $177 \cdot 8$ & $81 \cdot 0$ & 55.0 \\
\hline
\end{tabular}

bones (expressed as mass of mineral per unit length) was measured by photon absorptiometry at the midpoint of the radius, identified by palpation of the distal ulnar styloid process and the proximal tip of the olecranon. Ulnar length was defined as the distance between these sites, measured with dividers before the scan. A regression equation was used to estimate from the ulnar length the position of the midshaft of the radius relative to the distal ulnar styloid process. ${ }^{7}$ Technical details of the absorptiometer and its calibration using postmortem specimens have previously been described. ${ }^{7}$ The measured bone mineral content of the radius and ulna together is accurate to $\pm 6 \mathrm{mg}(95 \%$ confidence limits). Precision, calculated from the duplicate values of bone mineral content obtained during every investigation, was $5 \%$ in the two groups combined.

At the same time as the bone mineral content was measured an anteroposterior radiograph of the right forearm was taken in the preterm infants under standardised radiographic conditions. The radiographs were assessed, with infant identification obscured, by a radiologist (RA) using the scoring method of Koo et al. ${ }^{2}$ Grade 0 was allocated to infants with normal bones, 1 to those with mineral rarefaction only, 2 to those with fraying and cupping of the metaphyses - that is, abnormalities observed in rickets, and 3 to those who also had fractures.

A blood sample was obtained from each preterm infant on the same day and assayed for plasma alkaline phosphatase activity ${ }^{8}$ using a Technicon analyser (type RA 1000).

Crown-heel length was measured with a standard infantometer.

Statistical analysis of the data included Student's $t$ test, Pearson's correlation coefficient, and analysis of variance and covariance. Two tailed probabilities are given throughout.

\section{Results}

Table 1 contains the observations on the preterm infants at a postconceptional age of 40 weeks. Table 2 contains the reduced set of observations on the full term infants shortly after birth.

Table 3 Correlation matrix of observations on the preterm group

\begin{tabular}{|c|c|c|c|c|c|c|c|}
\hline & $\begin{array}{l}\text { Gestational } \\
\text { age at } \\
\text { birth }\end{array}$ & $\begin{array}{l}\text { Weight at } \\
\text { birth }\end{array}$ & $\begin{array}{l}\text { Weight at } \\
40 \text { weeks }\end{array}$ & $\begin{array}{l}\text { Bone } \\
\text { mineral } \\
\text { content }\end{array}$ & $\begin{array}{l}\text { Koo } \\
\text { score }\end{array}$ & $\begin{array}{l}\text { Alkaline } \\
\text { phosphatase }\end{array}$ & $\begin{array}{l}\text { Ulnar } \\
\text { length }\end{array}$ \\
\hline Weight at birth & $0.79 \ddagger$ & & & & & & \\
\hline Weight at 40 weeks & NS & NS & & & & & \\
\hline Bone mineral content & NS & NS & $0.73 \ddagger$ & & & & \\
\hline Koo score & NS & $-0.66 \dagger$ & $-0.60^{*}$ & $-0.61 \dagger$ & & & \\
\hline Alkaline phosphatase & $-0.61 \dagger$ & $-0 \cdot 79 \ddagger$ & NS & NS & $0 \cdot 61 \dagger$ & & \\
\hline Ulnar length & NS & NS & $0.94 \ddagger$ & $0.82 \ddagger$ & $-0 \cdot 58^{*}$ & NS & \\
\hline
\end{tabular}

${ }^{*} \mathrm{p}<0.05$. $\dagger \mathrm{p}<0.01 . \neq \mathrm{p}<0.001$.

NS $=$ Not significant. 
Internal relations between observations in preterm infants. Table 3 is a correlation matrix of the measurements on the preterm infants. Bone mineral content was not significantly correlated with weight at birth but was highly significantly correlated with weight at 40 weeks, ulnar length, and crown-heel length $(p<0 \cdot 001)$. Bone mineral content was significantly correlated with Koo score $(p<0.01)$ but not with plasma alkaline phosphatase activity. In contrast, Koo score was significantly correlated with weight at birth $(p<0.01)$, weight at 40 weeks $(\mathrm{p}<0.05)$, and plasma alkaline phosphatase activity $(\mathrm{p}<0 \cdot 01)$. Plasma alkaline phosphatase activity was significantly inversely correlated with gestational age $(p<0.01)$ and weight at birth $(p<0.001)$.

Comparison of preterm and full term groups. Table 4 contains the mean values, standard deviations, and standard errors of the measurements for the preterm and full term groups, with the results of $t$ tests. At 40 weeks preterm infants tend to be shorter, weigh less, and have a lower bone mineral content than full term infants.

Table 5 contains the results of analysis of variance and covariance of ulnar length. Both maturity and weight at 40 weeks are significant sources of variation in ulnar length $(p<0 \cdot 001)$. When measurements of ulnar length are adjusted for weight at 40 weeks a significant difference remains between the groups $(p<0 \cdot 001)$. For a given weight, preterm infants tend to have shorter forearms and lower values for crown-heel length $(p<0 \cdot 001)$ than full term infants.

Given that preterm infants are generally shorter and lighter than full term infants at 40 weeks (Table 4), the same approach was used to establish whether, when both weight at 40 weeks and ulnar length are taken into account, a difference in bone mineral content still exists between the groups. These results are also given in Table 5. The difference between the adjusted mean values remains highly significant $(p<0.005)$, indicating that

Table 4 Comparison of the mean values of the observations on preterm and full term infants

\begin{tabular}{|c|c|c|c|c|c|c|c|c|}
\hline \multirow[t]{2}{*}{ Variable } & \multicolumn{3}{|c|}{ Preterm group $(n=17)$} & \multicolumn{3}{|c|}{ Full term group $(n=15)$} & \multirow[t]{2}{*}{$t$ Value } & \multirow[t]{2}{*}{ p Value } \\
\hline & Mean & $S D$ & $S E$ & Mean & $S D$ & $S E$ & & \\
\hline Weight at birth (g) & 1380 & 395 & 96 & 3539 & 543 & 140 & $-13 \cdot 0$ & $<0 \cdot 001$ \\
\hline Weight at 40 weeks (g) & 2666 & 972 & 236 & (3539) & $(543)$ & $(140)$ & $-3 \cdot 1$ & $<0 \cdot 01$ \\
\hline Bone mineral content $(\mathrm{mg} / \mathrm{cm})$ & $113 \cdot 3$ & $40 \cdot 3$ & $9 \cdot 8$ & $194 \cdot 0$ & $14 \cdot 3$ & $3 \cdot 7$ & $-7 \cdot 7^{*}$ & $<0 \cdot 001$ \\
\hline Koo score & $0 \cdot 88$ & - & - & - & - & - & - & - \\
\hline Ulnar length (mm) & $71 \cdot 74$ & $6 \cdot 77$ & 1.64 & $81 \cdot 73$ & 3.84 & 0.99 & $-5 \cdot 0$ & $<0 \cdot 001$ \\
\hline Crown-heel length $(\mathrm{cm})$ & 46.07 & $4 \cdot 83$ & $1 \cdot 17$ & 53.80 & $3 \cdot 37$ & $0 \cdot 87$ & $-5 \cdot 2$ & $<0.001$ \\
\hline
\end{tabular}

${ }^{*} t$ Test with unequal variances.

Table 5 Results of analysis of variance and covariance of ulnar length and bone mineral content

(a) Sources of variability in all 32 infants, including maturity.

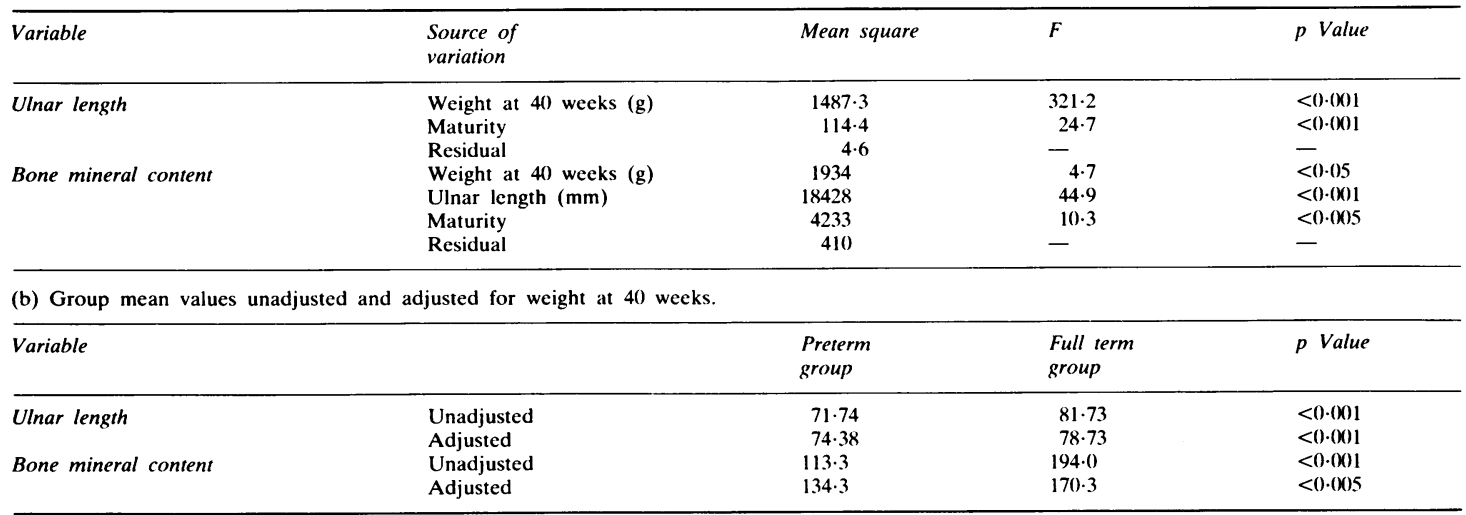


the bones of preterm infants are disproportionately undermineralised even when allowance is made for body size.

\section{Discussion}

The terminology used in neonatal bone disease is confusing. Rickets of prematurity implies the presence of radiologically detectable abnormalities at the ends of the long bones and is historically related to vitamin D deficiency. ${ }^{9}$ These abnormalities, however, can occur in neonates, despite normal plasma vitamin D concentrations. ${ }^{1}$ Osteopenia of prematurity, while a better term than rickets, implies a deficit in bone mineral that is difficult to quantify radiologically.

In preterm infants we found a significant but weak relation between radiological appearance and bone mineral content at a postconceptional age of 40 weeks. Four of the six infants with a normal Koo score had bone mineral content values between 3.7 and 6.5 standard deviations below the mean for infants born at term. Previous work on adult bones has shown that substantial demineralisation has to occur before radiological changes become apparent, ${ }^{4}$ and our results further emphasise the limitations of radiological assessment even if a standardised scoring system is used. To depend on radiology for the diagnosis of osteopenia will result in serious underestimation of the extent of this condition. Furthermore, therapeutic studies aimed at correction either by using vitamin D supplements or by enhancing substrate intake may give misleading results if undue reliance is given to apparent radiological improvement. Although calcium supplementation has been shown to result in radiological improvement, ${ }^{10}$ the lack of precision of radiological assessment is such that small changes in bone mineral content are unlikely to be detected.

At a postconceptional age of 40 weeks the preterm infants in this study were lighter and shorter than infants born at 40 weeks. Although the mean bone mineral content for the preterm group was reduced relative to the full term group, this could have been the result of preterm infants having smaller bones, because bone mineral content is dependent on size. ${ }^{11}$ When analysis of variance was used to correct for both weight and ulnar length, however, the mean bone mineral content was still significantly reduced in the preterm group. The observed reduction in bone mineral content cannot be explained solely on the basis of body size and must therefore contain a component due to underlying metabolic bone disease.

Plasma alkaline phosphatase activity increases with postnatal age, and peak values are found at a time near to what should have been term. ${ }^{3}$ Many variables affect its assay, ${ }^{5}$ and the range of values in infants with radiological bone disease overlaps the range in those with normal bones to such an extent that absolute values are of limited use. ${ }^{6}$ Although we found alkaline phosphatase activity to be related to Koo score, it was not significantly correlated with bone mineral content. It has been suggested that activities up to five times the upper limit of the adult range should be regarded as normal in growing preterm infants, while activities exceeding six times the upper limit (which for our laboratory is $13 \mathrm{KA}$ units) are suggestive of underlying radiological bone disease. ${ }^{5}$ In our study three of the four infants whose plasma alkaline phosphatase activity exceeded 78 KA units had abnormal Koo scores, and two had particularly low values of bone mineral content. While very high plasma alkaline phosphatase activities may occur in association with frank radiological bone disease, however, normal activities are also found in those with osteopenia. Thus neither radiological assessment nor plasma alkaline phosphatase activity can reliably detect undermineralisation in the bones of growing preterm infants. At present photon absorptiometry, although primarily a research tool, seems to be the only viable technique for diagnosing osteopenia of prematurity.

Although the mean gestational age of the preterm infants was just under 30 weeks, many considerably less mature infants now survive. Only two of the 17 infants in our preterm group had bone mineral content values within the norml range for infants born at term. It is more than likely therefore that any infant born before 28 weeks will develop osteopenia even in the absence of obvious radiological or biochemical abnormalities. Sequential measurements of bone mineral content in premature infants have shown that the postnatal increase in bone mineral content is significantly less than that expected in utero, ${ }^{12}{ }^{13}$ and while the long term consequences are unknown this problem and its treatment merit further investigation.

J R James holds a Research Fellowship awarded by the Yorkshire Regional Health Authority. The authors are grateful to Dr D H Marshall, MRC Mineral Metabolism Unit, for his advice on the statistical analysis of the data and to Cow and Gate for financial support.

\section{References}

${ }^{1}$ McIntosh N, Livesey A, Brooke OG. Plasma 25-hydroxyvitamin $\mathrm{D}$ and rickets in infants of extremely low birthweight. Arch Dis Child 1982;57:848-50.

2 Koo WWK, Gupta JM, Nayanar VV, Wilkinson M, Posen S. Skeletal changes in preterm infants. Arch Dis Child 1982;57:447-52.

${ }^{3}$ Kovar I, Mayne P. Plasma alkaline phosphatase activity in the preterm neonate. Acta Paediatr Scand 1981;70:501-6. 
876 James, Congdon, Truscott, Horsman, and Arthur

${ }^{4}$ Lachman E. Osteoporosis: the potentialities and limitations of its roentgenologic diagnosis. American Journal of Roentgenology 1955;74:712-5.

5 Kovar I, Mayne P, Barltrop D. Plasma alkaline phosphatase activity: a screening test for rickets in preterm neonates. Lancet 1982;i:308-10.

${ }^{6}$ McIntosh N. Rickets of prematurity. Bone 1984;1:26-7.

7 James J, Congdon P, Truscott J, Horsman A. Measurement of bone mineral content in the human fetus by photon absorptiometry. Early Hum Dev 1986;13:169-81.

${ }^{8}$ Morgenstern S, Kessler G, Auerbach J, Flor RV, Klein B. An automated p-nitrophenylphosphate serum alkaline phosphatase procedure for the autoanalyser. Clin Chem 1965;11:876-88.

${ }^{9}$ Brooke OG, Lucas A. Metabolic bone disease in preterm infants. Arch Dis Child 1985;60:682-5.

10 Day GM, Chance GW, Radde IC, Reilly BJ, Park E, Sheepers J. Growth and mineral metabolism in very low birth weight infants. II Effects of calcium supplementation on growth and divalent cations. Pediatr Res 1975;9:568-75.
11 Horsman A, Bulusu L, Bentley HB, Nordin BEC. Internal relationships between skeletal parameters in twenty three male skeletons. In: Cameron JR, ed. Proceedings of bone measurement conference. Springfield, Virginia: US Department of Commerce, 1970:365-81.

12 Minton S, Steichen JJ, Tsang RC. Bone mineral content in term and preterm appropriate for gestational age infants. $J$ Pediatr 1979;95:1037-42.

13 Minton S, Steichen JJ, Tsang RC. Decreased bone mineral content in small for gestational age infants compared with appropriate for gestational age infants. Pediatrics 1983;71: 383-8.

Correspondence to Dr P J Congdon, Regional Neonatal Surgical and Intensive Care Unit, Clarendon Wing, The General Infirmary, Leeds LS1 3EX, England.

Received 5 June 1986 